\title{
La mayor densidad mamográfica basal se asoció a cáncer de mama
}

\author{
Breast cancer patients had greater density on basal mammographic exams
}

Boyd NF y col. N Engl J Med. 2007 Jan 18;356(3):227-36

\section{Objetivo}

Describir la asociación entre densidad mamográfica basal y riesgo de cáncer de mama.

\section{Diseño}

Casos y controles anidado en una cohorte*.

\section{Lugar}

Canadá.

\section{Pacientes}

Los casos y los controles se seleccionaron de tres cohortes prospectivas de rastreo de cáncer de mama.

\section{Medición de resultados principales}

La densidad en las mamografías fue evaluada por dos radiólogos independientes y un método computarizado. Cada imagen fue clasificada en una de seis categorías de densidad.

\section{Resultados principales}

Luego de ajustar por edad, índice de masa corporal, edad de la menarca, número de partos, edad del primer parto, edad de la menopausia, terapia de reemplazo hormonal y cáncer de mama en familiares de primer grado; se observó asociación entre cáncer mamario y la proporción de superficie con alta densidad mamaria. Ver tabla 1.
Para los cánceres detectados por rastreo se estimó un OR de 3,5 (IC95\%: 2,0 a 6,2) para los cánceres detectados hasta 12 meses luego del monitoreo, un OR de 17,8 (IC95\%: 4,8 a 65,9) y para los detectados luego de los 12 meses, OR 5,7 (2,1 a 15,5). Ver tabla 1.

Tabla 1: asociación entre cáncer mamario y la densidad mamográfica.

\begin{tabular}{l|c|c|c}
$\begin{array}{c}\text { Densidad } \\
\text { mamográfica }\end{array}$ & Casos (n=1112) & Gontroles (n=1112) & Odds Ratio (IC 95\%) \\
\hline Menor a $\mathbf{1 0 \%}$ & 230 & 362 & 1 \\
\hline $\mathbf{1 0}$ a $\mathbf{2 5 \%}$ & 272 & 270 & $1,8(1,4$ a 2,2$)$ \\
\hline $\mathbf{2 5}$ a $\mathbf{5 0} \%$ & 336 & 290 & $2,1(1,6$ a 2,6$)$ \\
\hline $\mathbf{5 0}$ a $\mathbf{7 5 \%}$ & 178 & 144 & $2,4(1,8$ a 3,3$)$ \\
\hline Mayor a $\mathbf{7 5 \%}$ & 96 & 46 & $4,7(3,0$ a 7,4$)$ \\
\hline
\end{tabular}

\section{Conclusiones}

La mayor densidad mamográfica basal se asocia a un aumento de riesgo de cáncer de mama que persiste en el tiempo. Por otra parte, la mamografía anual en mujeres con densidad extensa no parece mejorar la tasa de detección de cáncer, por lo que se proponen nuevas formas de rastreo como mamografía digital, la ecografía o la resonancia nuclear magnética.

Palabras clave: cáncer de mama, factores de riesgo, densidad mamográfica. Key words: breast cancer, risk factors, mammographic density. Fuente de financiamiento: Instituto Nacional del Cáncer de Canadá

\section{Comentario}

Este estudio evalúa retrospectivamente, pero a partir de datos de una cohorte, la distribución de un posible factor de riesgo de cáncer de mama -la densidad mamográfica extensa- en pacientes con y sin cáncer de mama. De acuerdo a los valores de asociación reportados (homogéneos en las tres cohortes) es posible interpretar que es bastante más probable el antecedente de mamas mamográficamente densas en mujeres con cáncer de mama en comparación con los controles.

Si bien debido al diseño implementado y a que la densidad mamaria podría actuar como un enmascarador de lesiones coexistentes que podrían asociarse con malignidad, no es posible establecer causalidad, la prolijidad del estudio y la contundencia de sus resultados (odds ratio significativos, efecto dosis-respuesta) apoyan la evidencia sugerida por estudios previos que señalan a la densidad mamográfica extensa como un factor asociado al cáncer mama.
El cáncer de mama del intervalo entre dos rastreo es una importante causa de litigio a radiólogos. Cabe preguntarnos qué métodos complementarios de rastreo podrían aplicarse para el caso de mujeres con mamas densas'. Tal vez una opción sería la ecografía mamaria², que si bien ya cuenta con una clasificación BIRADS* para ser informada, aún no cuenta con estudios apropiados que la validen como estrategia de rastreo masivo.

\section{Conclusiones de los comentadores}

En pacientes con mamas muy densas podría contemplarse el uso de ecografía, mamografía digital o resonancia magnética para completar el rastreo ${ }^{1-3}$, aunque todavía no queda claro el método de elección ni el intervalo adecuado del mismo.

Ver glosario*

Gabriel Villalón y Maia Burstein [ Servicio de Medicina Familiar y Comunitaria. Hospital Italiano de Buenos Aires. ] Comentado de Boyd NF et al.Mammographic Density and the Risk and Detection of Breast Cancer. N Engl J Med. 2007 Jan 18;356 (3):227-36. PMID 17229950.

\section{Referencias}

1. Pisano ED et al. Diagnostic performance of digital versus film mammography for breast-cancer screening. N Engl J Med 2005; $353: 1773-1783$.

2. Crystal P.et al. Using sonography to screen women with mammographically dense breasts. AJR Am J Roentgenol 2003;181:177-182.

3. Wright $\mathrm{H}$ et al. Magnetic resonance imaging as a diagnostic tool for breast cancer in premenopausal women. Am J Surg 2005; 190:572-575. 